\title{
IRON METABOLISM. IRON STORES IN MAN AS MEASURED BY PHLEBOTOMY ${ }^{1}$
}

\author{
By DONALD HASKINS,2 ALEXANDER R. STEVENS, JR., ${ }^{3}$ STUART FINCH,2 AND \\ CLEMENT A. FINCH 4 \\ (From the Department of Medicine, University of Washington Medical School, Seattle, Wash.; \\ the Medical Clinic of the Peter Bent Brigham Hospital, and the Harvard \\ Medical School, Boston, Mass.)
}

(Submitted for publication February 1, 1952; accepted March 24, 1952)

Hemosiderin and ferritin represent storage iron, available for hemoglobin synthesis when need arises. Previous observations $(1,2)$ have indicated that these stores must be depleted before iron deficiency becomes manifest in the circulating red cell mass. The depletion of iron stores associated with normal hematological measurements may therefore be regarded as the "preclinical " phase of iron deficiency.

Interest in the pathogenesis of iron deficiency anemia has led us to further methods of evaluating iron stores. A rough estimate of iron reserves may be obtained by examination of sternal marrow for hemosiderin (2). A more quantitative measurement may be made by determination of iron mobilized for red cell production following phlebotomy. Data obtained by the latter technique are presented to define the size of the iron storage compartment in order to determine its availability and rate of replenishment in normal adult males and in subjects with abnormalities of iron metabolism.

\section{METHODS}

Volunteers were repeatedly phlebotomized as previously described (3). A balance sheet was kept on each subject recording the amount of iron removed by phlebotomy and the weekly change in red cell mass expressed in $\mathrm{mg}$. of iron. Repeated blood volumes were performed in each subject, in some individuals weekly over a period of two months. Despite the development of anemia the total blood volume showed no change thought to be sig-

1 These studies were supported by grants-in-aid from the United States Public Health Service and the Atomic Energy Commission.

${ }^{2}$ Research Associate at the Peter Bent Brigham Hospital, Boston, Mass.

3 Associate in Medicine at the University of Washington Medical School, formerly Public Health Research Fellow at the National Institutes of Health.

4 Associate Professor of Medicine, University of Washington Medical School. nificant. The current RBC mass was calculated by multiplying the average blood volume by the hematocrit.

The iron balance was determined for each weekly period. All figures were expressed in terms of $\mathrm{mg}$. iron, using a value of $1.1 \mathrm{mg}$. iron $/ 1.0 \mathrm{ml}$. packed red cells. The calculations 5 involved the following steps :

1). $\mathrm{ml}$. packed red cells removed $\times 1.1=$ total $\mathrm{mg}$. iron removed.

2). ( $\mathrm{ml}$. red cell mass at beginning of week minus $\mathrm{ml}$. red cell mass at end of week) $\times 1.1=\mathrm{mg}$. iron deficit in circulating red cell mass.

3). (1) $-(2)=\mathrm{mg}$. iron mobilized for hemoglobin synthesis. The figure represents "available" iron.

During the experimental period an unknown amount of iron was absorbed. Previous studies indicated that $3 \mathrm{mg} . /$ day represents maximal iron absorption from a normal diet (3). This correction was made in converting "available" to storage iron (Table I).

Blood for hematocrit determination was centrifuged in Wintrobe Tubes for one hour at 3,000 r.p.m. (centrifuge radius 6 inches). Blood volumes were determined by the method of Gibson and Evelyn, with a correction factor of 0.85 (4). Serum iron was determined by the method of Kitzes, Elvehjem, and Schuette (5).

\section{EXPERIMENTAL PROCEDURE}

Subjects were phlebotomized approximately $500 \mathrm{ml}$. weekly for seven weeks. In those instances where iron stores were limited, the degree of anemia produced necessitated cessation of the bleedings before the seventh week. All but one subject were on normal diets with estimated iron content between 10 and $20 \mathrm{mg}$./day. For descriptive purposes our subjects have been divided into six categories.

5 Sample calculation:

Basal blood volume $5,000 \mathrm{ml}$.

Week 4-hematocrit $40.0 \%$; erythrocyte mass 2,000 $\mathrm{ml}$.

Week 5-hematocrit $38.4 \%$; erythrocyte mass 1,920 ml.

$200 \mathrm{ml}$. erythrocytes removed by phlebotomy at week 4.

1). $200 \times 1.1=220 \mathrm{mg}$. iron removed.

2). $(2,000-1,920) \times 1.1=88 \mathrm{mg}$. iron deficit in erythrocyte mass.

3). $220-88=132 \mathrm{mg}$. "available" iron. 
TABLE I

Storage iron mobilized in seven weeks

\begin{tabular}{l|c|c|c}
\hline \hline & $\begin{array}{c}\text { Iron re- } \\
\text { moved }\end{array}$ & $\begin{array}{c}\text { Available } \\
\text { iron* }\end{array}$ & $\begin{array}{c}\text { Per cent of } \\
\text { iron removed } \\
\text { replaced by } \\
\text { storage iron }\end{array}$ \\
\hline & $m g$. & & \\
I. Normal & 1,704 & $844-991$ & $\mathbf{5 0 - 5 8 \%}$ \\
II. Prefed with iron & 1,626 & $890-1,037$ & $\mathbf{5 5 - 6 4 \%}$ \\
III. Iron depleted & 1,150 & $93-198$ & $8-17 \%$ \\
IV. Oral iron & 1,810 & $1,294-1,441$ & $71-80 \%$ \\
V. Enlarged iron reserves & 1,518 & $920-1,067$ & $61-70 \%$ \\
VI. Hemochromatosis & 1,601 & $1,179-1,326$ & $71-83 \%$ \\
\hline
\end{tabular}

* The first figure represents allowance for maximal absorption of dietary iron ( $3 \mathrm{mg}$./day). The second figure is without allowance for absorption. True estimate of storage iron is probably between these two figures.

I. Normal iron stores. Two men, ages 25 and 30 years, in good health had no history of previous blood loss or iron administration. Blood values were normal. 6

II. Normal iron stores enhanced by oral iron. Two men, ages between 25 and 30 years, had taken iron by mouth (200 and $400 \mathrm{gm} . \mathrm{FeSO}_{4}$ ) over a six-month period up to one year before the start of this study. They also had normal hematological measurements.

III. Iron depleted. Two men, ages 26 and 33, had normal hematological measurements. Both had given numerous blood transfusions but none during the two months immediately preceding this study.

6 Reference to normal blood values indicates the following: red count 4.5 to $5.5 \times 10^{6} / \mathrm{cu} . \mathrm{mm}$., hemoglobin 14.5 to $16.5 \mathrm{gm} . / 100 \mathrm{ml}$, hematocrit $43-50 \%$, mean corpuscular volume $80-95$ cu. $\mu$, mean corpuscular hemoglobin concentration $31-36 \%$, serum iron $90-150 \mu \mathrm{gm} . /$ $100 \mathrm{ml}$.
IV. Supplementary oral iron during the phlebotomy period. Two young men were given 0.6 and $1.2 \mathrm{gm}$. FeSO, per day during the period of bleeding. Since no difference was observed in the response to the two doses of iron, they were grouped together. Hematological measurements were initially within normal limits.

V. Increased iron stores. Two men, ages 52 and 54, were brothers of patients with hemochromatosis. These subjects had no clinical evidence of the disease but had elevated serum iron values and an increase in sternal marrow hemosiderin.

VI. Hemochromatosis. Four patients, three male and one female, all with the diagnosis of hemochromatosis established by liver biopsy, had elevated serum iron and increased marrow hemosiderin.

Other hematological data in these subjects including hematocrit changes, serum iron values, and calculated rates of hematopoiesis may be found in a previous report (3).

\section{RESULTS}

The weekly mobilization of iron is portrayed in cumulative line graphs. In all experimental subjects there was a lag period of one week after the initial phlebotomy before iron stores were utilized for blood production.

Normal subjects (I and II) after seven phlebotomies showed evidence of iron depletion. Hematocrits had fallen to $33 \%$, and the rate of hematopoiesis was curtailed. Over these seven weeks 50 to $60 \%$ of the iron removed had been replaced from iron stores (Figure 1).

\section{SOURGE OF IRON REMOVED BY PHLEBOTOMY IN MAN}

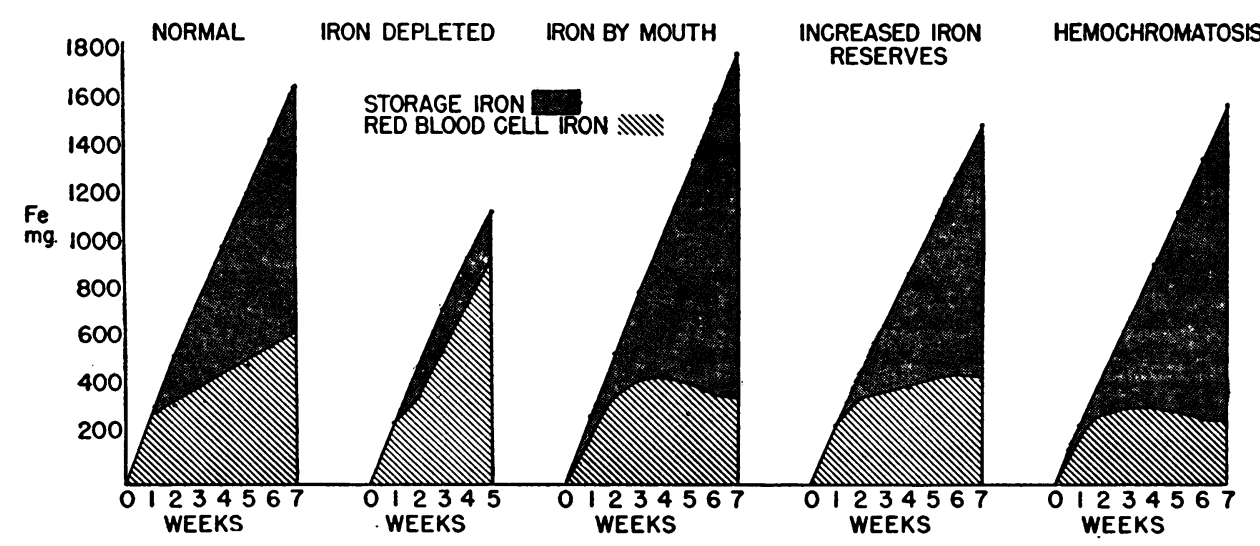

Fig. 1. The Cumulative Iron Balance Over a Seven-Week Phlebotomy Period

In each group, the sloping left-hand line indicates total iron removed by weekly $500 \mathrm{ml}$. phlebotomies. The lower, cross-hatched area represents red cell iron deficit, calculated from the degree of anemia, and the remaining upper area represents iron mobilized from the tissue stores. The available storage iron varies directly with the size of the body stores. Oral supplementary iron is as available as tissue stores, if given during the period of bleeding. 

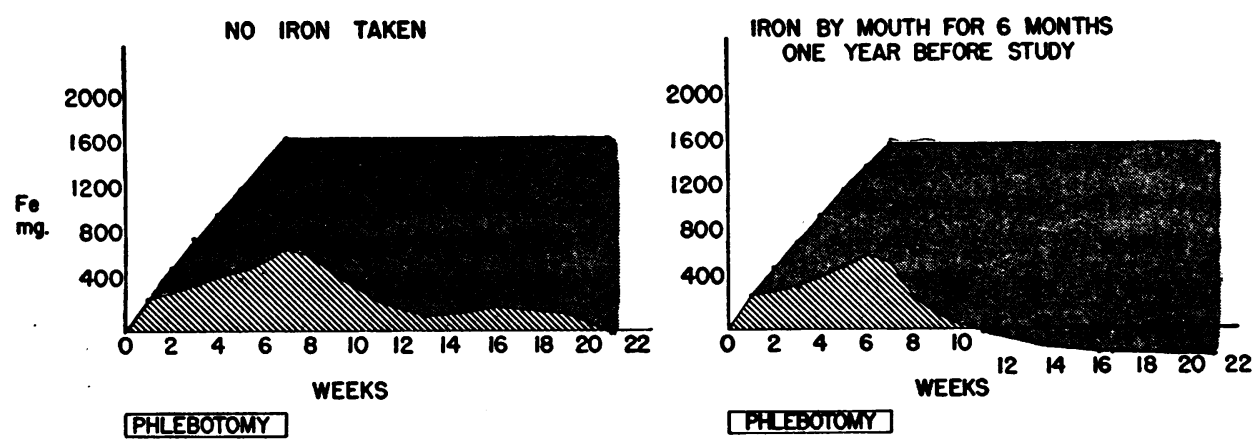

FIG. 2.

The "normal" group is here divided into two subjects who had taken no supplementary iron prior to the phlebotomy period (group I), and two subjects who had taken large amounts of ferrous sulfate one year before the study (group II). The latter pair showed a more rapid recovery and mobilized about $200 \mathrm{mg}$. more iron.

In the recovery period (Figure 2) a difference was discernible for the first time between I and II. Those individuals prefed iron overcame the red cell deficit by the 11th week, whereas in the normal subjects a deficit was present until the 21st week. Total storage iron available for hemoglobin production over a 14-week period in group I was 1,200 to $1,500 \mathrm{mg}$. and in group II, $1,450-1,750$ $\mathrm{mg}$.

Previously phlebotomized subjects with normal hemograms at the time of the study (group III) tolerated bleeding poorly (Figure 1). After removal of $2,500 \mathrm{ml}$. of blood no more than $200 \mathrm{mg}$. of iron had been mobilized from stores, and the hematocrit had fallen below $30 \%$. To exclude the possibility that lack of iron mobilization might be due to impaired hematopoiesis from other causes, these subjects were fed iron with an excellent hematopoietic response.

To investigate further the effect of previous blood loss on iron stores, subject D. H., one of the normal group, was bled again one year after the initial course of phlebotomies. In the interim he had been on a normal diet without iron supplements. Red cell measurements and serum iron had returned to normal. Four phlebotomies resulted in a more severe anemia and less mobilization of iron than the year before (Figure 3 ).

In subjects given iron by mouth (group IV), in those with increased iron reserves (V) and in patients with hemochromatosis, from 61 to $83 \%$ of the iron removed was replaced by storage iron (Figure 1).

\section{DISCUSSION}

Iron stores provide protection against the development of iron deficiency anemia. The direct relationship between the presence of adequate iron stores and the ability to accelerate blood production after blood loss has been previously discussed (3). It is our further conviction that if hemo-

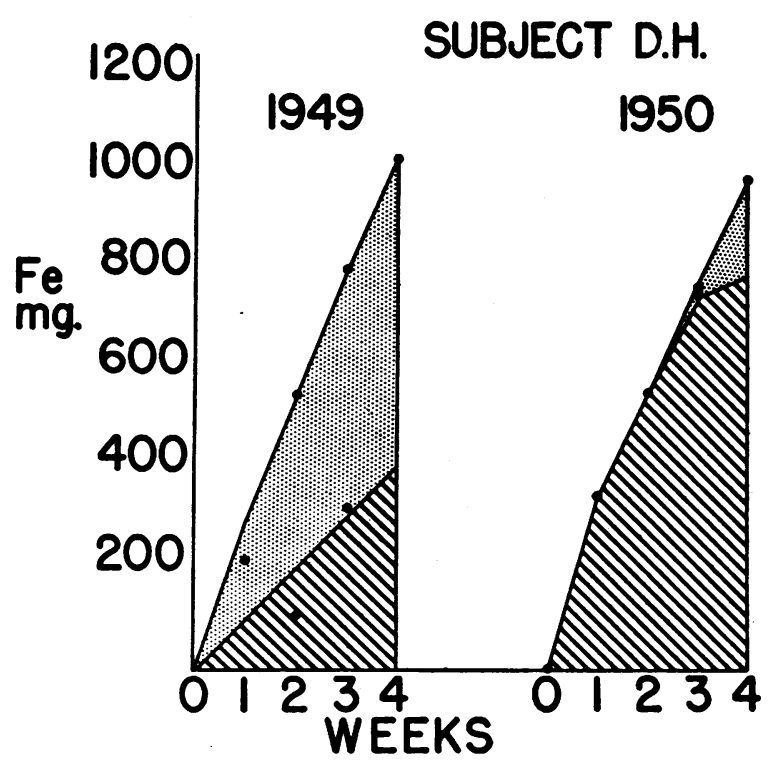

FIG. 3.

Subject D. H. of group I was followed to recovery of blood and serum iron from the first seven-week phlebotomy period, and was subjected to similar bleedings one year later. There was an evident lack of available storage iron during the second study. The exhausted stores had not been repleted during one year on a normal diet, despite the prompt restoration of normal hemoglobin levels. 
siderin and ferritin are present in tissues, this storage iron is available for blood production (1). This is borne out by the absence of hemosiderin in the marrow in iron deficiency anemia (6).

Little attention has been given to the quantitation of iron stores in man. Hynes (7) calculated iron reserve in one subject to be about 600 mg. after repeated small bleedings during a period of over 100 days. Hahn (8), by chemical analysis of iron deficient and normal dogs, has estimated storage iron to be $20 \%$ of total body iron. Translated to man with approximately $4.5 \mathrm{gm}$. of body iron, this would represent $900 \mathrm{mg}$. of storage iron.

Our studies were designed to minimize effects of absorption by removing large amounts of iron over a short period of time. Since previous observations indicate that a normal diet contributes a maximum of about $3 \mathrm{mg}$. iron for hemoglobin production per day (3), correction for diet will change our figures of storage iron relatively little (Table I). It is also assumed that the "pull" on iron stores is probably directly related to the degree of anemia: the greater the anemia, the greater the rate of iron mobilization (9). This would tend, if anything, to reduce the differences observed between the groups, since those patients with smaller stores would develop a greater degree of anemia and therefore a greater "pull" on iron remaining in their tissues.

In normal adults approximately $900 \mathrm{mg}$. of iron were mobilized in seven weeks and 1,200 to 1,500 in 14 weeks. This is taken to represent most of the iron stores of these individuals since hematopoiesis was retarded from lack of iron, the serum iron remained depressed for many months, and one subject bled again one year later had practically no iron reserve at that time.

In patients with increased iron stores, about $80 \%$ of the red cell iron removed by phlebotomy was replaced from tissue iron stores over seven weeks. In the patient with hemochromatosis, if bleedings are continued, replacement reached $100 \%$ as the initially induced anemia regresses despite the continued weekly phlebotomies.

Of particular clinical interest is the individual with decreased iron stores. It is to be expected in iron deficiency anemia that blood loss will be reflected quantitatively in the circulating red cell mass. However, it is also evident that subjects with a history of previous blood loss (group III) may have completely normal hematological values, yet have depleted stores and show almost as great a vulnerability to iron loss.

An attempt was made to measure the repletion of iron stores in one individual (D. H.) one year after the initial series of phlebotomies. As indicated by Figure 3, a normal diet appears to result in a negligible accumulation of iron over this period of time. In another subject (group III) a series of phlebotomies had been followed by six months of iron ingestion (200 gm. $\left.\mathrm{FeSO}_{4}\right)$. Phlebotomies performed subsequently showed negligible iron stores.

Our observations are similar to those reported by Fontès and Thivolle (10) based on tissue iron analyses. In dogs made anemic by bleeding, oral iron was administered for six weeks, restoring the peripheral blood to normal. At this time tissue iron stores were non-existent. Similarly in anemic dogs on supplementary iron for six to 12 months, iron reserves were found to be only one-third to one-half of normal. It would appear that orally administered iron is absorbed in increased amounts until anemia is corrected, but that iron stores are not easily reconstituted by the oral route. One is impressed that iron stores are accrued gradually over many years, and when depleted are rebuilt slowly.

There is considerable question also whether orally administered iron is effective in increasing iron stores above normal, in contrast to its efficacy in the treatment of anemia. In animals on a normal diet it is difficult to increase body iron unless very large amounts of iron are administered (1, 11). Similarly, in this study the prefeeding of iron (group II) had little effect on the amount of available iron. Iron feeding for six months increased iron stores by about $200 \mathrm{mg}$.

The availability of iron from the diet and from stores may be compared on the basis of the data presented. Three separate situations should be distinguished-1) adequate iron stores, 2) medicinal iron by mouth, 3) normal diet with iron content of approximately $15 \mathrm{mg}$./day. In subjects with abundant storage iron 30 to $40 \mathrm{mg}$. of iron were available daily for hemoglobin production. 
Medicinal iron given orally supplies comparable amounts of iron for hemoglobin production. However, previous studies indicate that an average of only $3 \mathrm{mg}$. of dietary iron is available in the iron-deficient subject. Since the normal bone marrow uptake daily for hemoglobin synthesis is about $25 \mathrm{mg}$., stores may allow an increase of up to $150 \%$ above normal, while dietary iron allows an increase of $15 \%$. Thus the individual with adequate iron stores is ten times as effective in accelerating hematopoiesis following blood loss as the individual with depleted stores who must derive iron from his diet.

\section{SUMMARY}

Available iron stores in man may be measured by the mobilization of tissue iron in response to repeated phlebotomies. Retarded hematopoiesis toward the end of the bleeding period is assumed to indicate near depletion of available iron.

The normal adult male had iron stores of 1,200 to $1,500 \mathrm{mg}$., mobilized over a period of three to four months.

Prolonged iron feeding prior to the phlebotomies had little effect on the size of stores in the normal individual.

Once iron stores had been depleted, they were rebuilt slowly, either from a normal diet or from orally ingested supplementary iron.

\section{REFERENCES}

1. Finch, C. A., Hegsted, M., Kinney, T. D., Thomas, E. D., Rath, C. E., Haskins, D., Finch, S., and Fluharty, R. G., Iron metabolism. The pathophysiology of iron storage. Blood, 1950, 5, 983.

2. Rath, C. E., and Finch, C. A., Sternal marrow hemosiderin; method for determination of available iron stores in man. J. Lab. \& Clin. Med., 1948, 33, 81.

3. Finch, S., Haskins, D., and Finch, C. A., Iron metabolism. Hematopoiesis following phlebotomy. Iron as a limiting factor. J. Clin. Invest., 1950, 29, 1078.

4. Gibson, J. G., II, Weiss, S., Evans, R. D., Peacock, W. C., Irvine, J. W., Jr., Good W. M., and Kip, A. F., The measurement of the circulating red cell volume by means of two radioactive isotopes of iron. J. Clin. Invest., 1946, 25, 616.

5. Kitzes, G., Elvehjem, C. A., and Schuette, H. A., The determination of blood plasma iron. J. Biol. Chem., 1944, 155, 653.

6. Stevens, A. R., Jr., Coleman, D. H., and Finch, C. A., Clinical evaluation of iron stores. To be published.

7. Hynes, M., The iron reserve of a normal man. J. Clin. Path., 1949, 2, 99.

8. Hahn, P. F., The metabolism of iron. Medicine, 1937, 16, 249.

9. Robscheit-Robbins, F. S., and Whipple, G. H., Hemoglobin production increases with severity of anemia. Am. J. Physiol., 1941, 134, 263.

10. Fontès, G., and Thivolle, L., Recherches expérimentales sur la thérapeutique de l'anémie grave par carence martiale et notamment par hémorragie; la reconstitution des réserves martiales. Le Sang, 1936, 10, 144.

11. Kinney, T. D., Hegsted, D. M., and Finch, C. A., The influence of diet on iron absorption; pathology of iron excess. J. Exper. Med., 1949, 90, 137. 